\title{
Study on stability bearing capacity of large size and eccentric bending members with different slenderness ratios
}

\author{
Z.b. $\mathrm{Li}^{1, \mathrm{a}}, \mathrm{C} . \mathrm{Y} . \mathrm{Yu}^{1, \mathrm{~b}}$ and Y.P. $\mathrm{Xie}^{2, \mathrm{c}}$ \\ ${ }^{1}$ The Key Laboratory of Urban Security and Disaster Engineering, MOE, Beijing Key Lab of \\ Earthquake Engineering and Structural Retrofit, Beijing University of Technology, Beijing 100124, \\ PR China \\ ${ }^{2}$ College of Exploration Technology and Engineering, HeBei GEO University, Shijiazhuang 050031, \\ China \\ alizb@bjut.edu.cn, ${ }^{\text {b15710061307@163.com, }}{ }^{c}$ axypa@163.com
}

\begin{abstract}
Keywords: Transmission towers; Thin-walled steel tubes; Slenderness ratio; ABAQUS finite element software; Instability.

Abstract. In this paper, the effect of slenderness ratio on the ultimate stability bearing capacity of the eccentric compressive members is analyzed. 10 specimens are analyzed by ABAQUS finite element software and steel structure code at home and abroad. This case is that the eccentric load is applied at both ends. The eccentric distance is $27.1 \mathrm{~mm}$. The slenderness ratios are 10, 20, 30, 40, 50, 60, 70, 80, 90 and 100, respectively. The results show that the numerical simulation results considering the initial imperfection are in good agreement with the theoretical results, and the two rules is similar; the results of standard calculation are basically the same in all countries; with the increase of slenderness ratio, the ultimate load decreases; as the slenderness ratio increases, the slope of the softening stage increases, which inflects a shift from ductility to instability; however, when the slenderness ratio is equal to or greater than 50, the transition of instability to ductility is expressed, and we can define this value as the critical value of different failure patterns.
\end{abstract}

\section{Introduction}

Steel tubes are widely used in the main force components of transmission towers because of the excellent mechanical properties of thin-walled steel tubes. However, the component may have different loading due to the actual construction deviation and additional bending moment, which includes reverse eccentric compression at both end, eccentric compression at one end, and same eccentric compression at both ends. According to the requirement of actual engineering, the stability bearing capacity of steel structure has always been a problem that designers and researchers pay attention to [3]. However, in practice, it is necessary to carry out a thorough study on its stability bearing capacity because of the instability failure of steel structures occurs at times. Domestic and foreign scholars have studied the steel members subjected to axial load and moment from different aspects. As early as the 18th century, the critical load for an ideal elastic column is often called the Euler load proposed by Euler. There are many existing stability theories, including elastic buckling and inelastic buckling. The effects of initial imperfection, initial eccentricity and residual stress on the stability of the bearing capacity of components cannot be ignored. Yang, L. Y. et al suggested that the optimum aspect ratio range of the axial compression members of the transmission tower is from 40 to 80 [7]. Study on stability of large diameter thin-walled steel tube bending member indicated that the stable bearing capacity of the specimens decreased with the increase of the slenderness ratio [6]. Study on slenderness ratio of UHV steel tube transmission tower showed that the slenderness ratio of the main member was not greater than 35 under action of end bending moment; the slenderness ratio of the secondary component is not more than 160 in terms of controlling vibration and reducing tower weight [8]. Study on the overall stability of axially compressed cold-formed thick-walled square and rectangular steel tubes indicated that stability coefficient was proposed separately for Q235 and Q345 cold-formed thick-walled square and rectangular steel tubes because of steel structures (GB50018-2002) and AISI S100-2016 were not suitable for thick-walled steel members [5]. In this 
paper, the relationship between stability bearing capacity of eccentric compression and slenderness ratio is discussed in terms of numerical simulation and theoretical calculation. This paper mainly studies the change of the bearing capacity of the component when the slenderness ratio is from 10 to 100. At the same time, whether results calculated by design codes matches the numerical simulation without residual stress. Then the appropriate suggestions are given.

\section{Simulation details}

Component design. The slenderness ratio is from 10 to 100 , and the increment is 10 . The dimensions of the components are shown in Table 1. Yield stress is $420 \mathrm{MPa}$. Modulus of elasticity is 200000MPa. Constitutive model is an ideal elastoplastic model, which is shown in Fig. 3. Component design is shown in Fig.1. Finite element model is shown in Fig.2. Material unit selects C3D8R solid element.

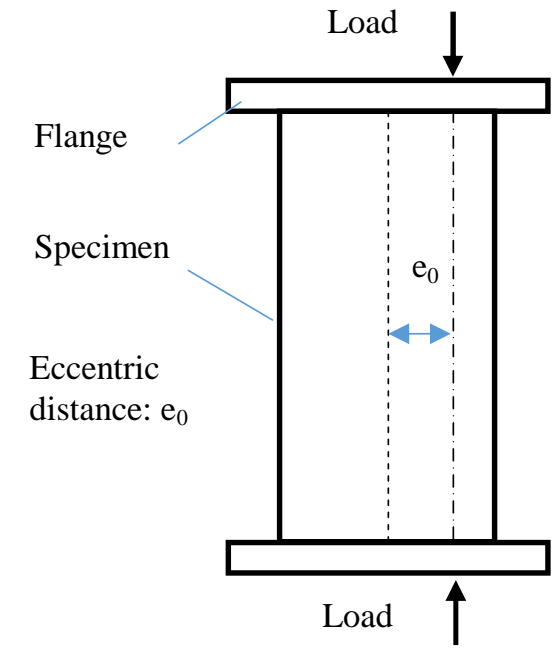

Fig.1 Member design

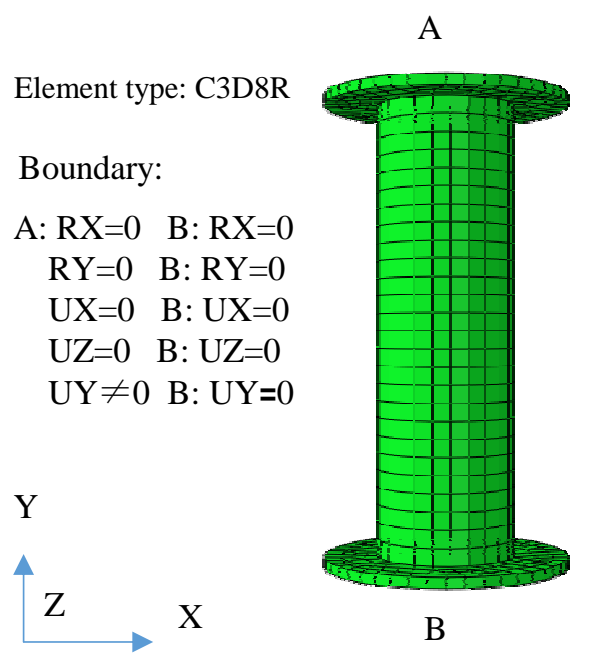

Fig. 2 Finite element model of eccentric member

Table 1 Component design

\begin{tabular}{|c|c|c|c|c|c|c|c|}
\hline & Slenderness & $\begin{array}{c}\text { Effective } \\
\text { length } \\
{[\mathrm{mm}]}\end{array}$ & $\begin{array}{c}\text { Eccentric } \\
\text { distance } \\
{[\mathrm{mm}]}\end{array}$ & $\begin{array}{c}\text { Outside } \\
\text { diameter } \\
{[\mathrm{mm}]}\end{array}$ & $\begin{array}{c}\text { Inside } \\
\text { diameter } \\
{[\mathrm{mm}]}\end{array}$ & $\begin{array}{c}\text { Flange } \\
\text { diameter } \\
{[\mathrm{mm}]}\end{array}$ & $\begin{array}{c}\text { Flange } \\
\text { height } \\
{[\mathrm{mm}]}\end{array}$ \\
\hline$\Phi 377 \times 8$ & $\begin{array}{c}10 \\
20 \\
30 \\
40 \\
50 \\
60 \\
70 \\
80 \\
90 \\
100 \\
\end{array}$ & $\begin{array}{c}1291.5 \\
2583.0 \\
3874.5 \\
5166.0 \\
6547.5 \\
7749.0 \\
9040.5 \\
10332.0 \\
11623.5 \\
12915.0 \\
\end{array}$ & 27.1 & 377 & 361 & 700 & 30 \\
\hline
\end{tabular}

Loading program of specimen. The types of component initial imperfection include initial bending and initial eccentricity, both of which reduce the bearing capacity of the component. There is no difference between the two effects in nature. Therefore, one of them is taken as the basis for calculating the compressive member. The imperfection values are shown in Table 2, whose value is $L / 1000$ [1]. The initial imperfection is applied to the member in the form of an equivalent eccentricity. 
Table 2 Initial imperfection

\begin{tabular}{cccc}
\hline Type of steel tube & Slenderness ratio & Effective length [mm] & Initial imperfection [mm] \\
\hline 10 & 1291.5 & 1.3 \\
& 20 & 2583.0 & 2.6 \\
& 30 & 3874.5 & 3.9 \\
\multirow{4}{*}{$577 \times 8$} & 50 & 5166.0 & 5.1 \\
& 60 & 6547.5 & 6.5 \\
& 70 & 7749.0 & 7.7 \\
& 80 & 9040.5 & 9.0 \\
& 90 & 10332.0 & 10.0 \\
& 100 & 11623.5 & 12.0 \\
\hline
\end{tabular}

\section{Simulation results and discussion}

Load and axial displacement curves. The relationship of load and displacement is shown in Fig. 3. Fig. 3(a) shown the eccentric loading without considering the initial imperfections. However, Fig. 3(b) was not. The load reduces as the slenderness ratio increased, and slope of softening stage increased as the slenderness ratio increased, which reflected the change from ductility to instability. That was opposite when the slenderness ratio was greater than 50. The relationship of load and slenderness ratio was shown in Fig. 4. The load reduced as the slenderness ratio increased, and the slope of reduction increased. However, that was contrary when the slenderness ratio was larger than 90. That could be seen that the load was larger than load considering eccentricity.

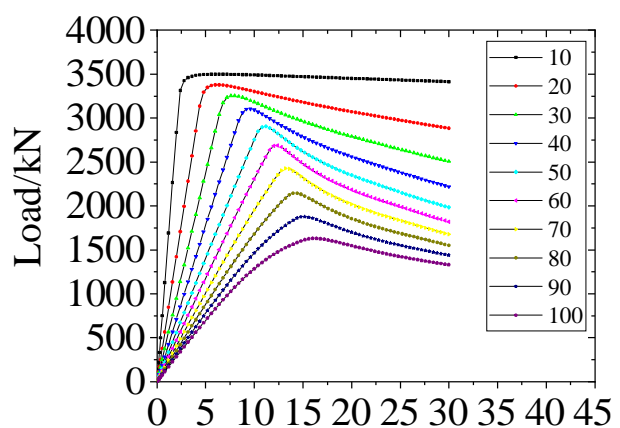

Axial displacement/mm

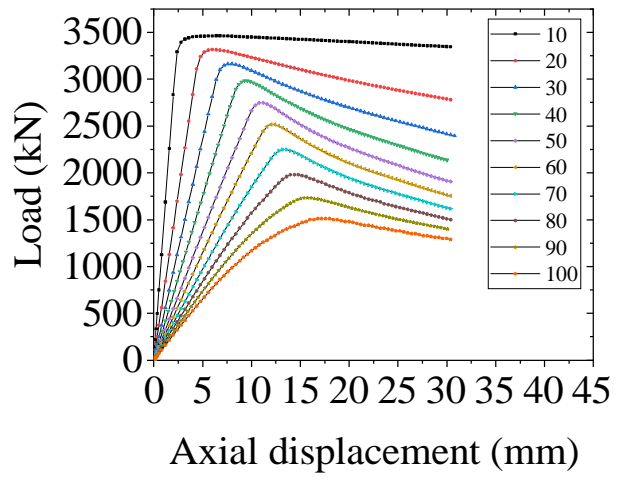

(b) Considering initial imperfection

(a) Without initial imperfection

Fig. 3 Load and displacement curves

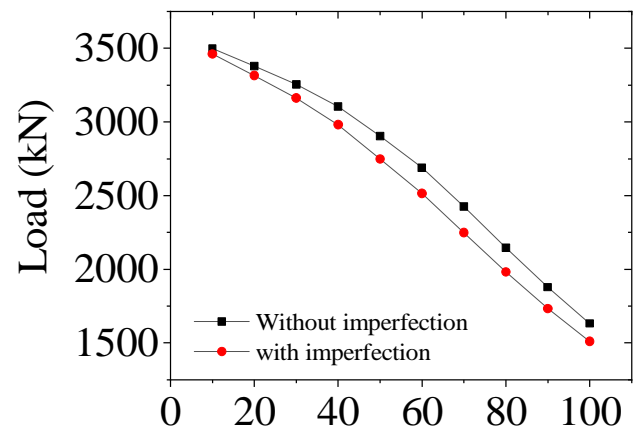

Slenderness ratio

Fig. 4 Relationship of load and slenderness 


\section{Theoretical calculation}

Chinese code [4]. The formula specified by the code of steel structures is

$$
\frac{N}{\varphi_{\mathrm{x}} A}+\frac{\beta_{\mathrm{mx}} M_{\mathrm{x}}}{\gamma_{\mathrm{x}}\left(1-0.8 \frac{N}{N_{\mathrm{Ex}}^{\prime}}\right) W_{1 \mathrm{x}}} \leq f_{\mathrm{y}}
$$

where $\beta_{\mathrm{mx}}=0.65+0.35 \frac{M_{2}}{M_{1}}=$ equivalent moment coefficient; $N=$ ultimate load; $\gamma_{\mathrm{x}}=$ plastic coefficient, $\varphi_{\mathrm{x}}=$ stability factor; $W_{1 \mathrm{x}}=$ section modulus; $N_{\mathrm{Ex}}^{\prime}=$ Euler load; $A=$ cross-sectional area; $f_{\mathrm{y}}=$ yield stress; $M_{\mathrm{x}}$ is ultimate moment produced by the ultimate load.

ANSI/AISC 360-2010 LRFD. The formula specified by the code of steel structures is When $\frac{P}{\Phi_{\mathrm{c}} P_{\mathrm{u}}} \geq 0.2$

$$
\frac{P}{\Phi_{\mathrm{c}} P_{\mathrm{u}}}+\frac{8}{9}\left(\frac{M_{\mathrm{ax}}}{\Phi_{\mathrm{b}} M_{\mathrm{ux}}}+\frac{M_{\mathrm{ay}}}{\Phi_{\mathrm{b}} M_{\mathrm{uy}}}\right) \leq 1
$$

when $\frac{P}{\Phi_{\mathrm{c}} P_{\mathrm{u}}} \leq 0.2$

$$
\frac{P}{2 \Phi_{\mathrm{c}} P_{\mathrm{u}}}+\frac{M_{\mathrm{ax}}}{\Phi_{\mathrm{b}} M_{\mathrm{ux}}}+\frac{M_{\mathrm{ay}}}{\Phi_{\mathrm{b}} M_{\mathrm{uy}}} \leq 1
$$

where $\Phi_{\mathrm{c}}$ and $\Phi_{\mathrm{b}}$ are resistance factor; $P_{\mathrm{u}}=\varphi_{\mathrm{y}} \mathrm{A} f_{\mathrm{y}} ; M_{\mathrm{ux}}$ or $M_{\mathrm{uy}}=W f_{\mathrm{y}} ; M_{a x}$ or $M_{a x}=M * \frac{\beta}{1-\mathrm{P} / \mathrm{P}_{\mathrm{E}}} ; \beta=$ $0.6+0.4 \frac{M_{2}}{M_{1}}$

when $\lambda \leq 4.71 \sqrt{E / f_{\mathrm{y}}}$

$$
\varphi_{\mathrm{y}}=0.658^{f_{\mathrm{y}} / f_{\mathrm{Ey}}}
$$

when $\lambda>4.71 \sqrt{E / f_{\mathrm{y}}}$

$$
\varphi_{\mathrm{y}}=0.877^{f_{\mathrm{y}} / f_{\mathrm{Ey}}}
$$

where $f_{E y}=\pi^{2} E / \lambda^{2} ; P=$ ultimate load; $P_{\mathrm{E}}=$ Euler load; $\varphi_{\mathrm{y}}=$ stability factor; $\lambda=$ slenderness ratio; $\mathrm{A}=$ cross-sectional area; $f_{\mathrm{y}}=$ yield stress; $\beta=$ equivalent moment factor; $W=$ section modulus; $M=$ ultimate moment produced by the ultimate load; $M_{1}$ and $M_{2}=$ end moment.

Design standard steel structure. The formula is shown as 


$$
\frac{P}{\phi_{\mathrm{p}} P_{\mathrm{uy}}}+0.85 \frac{M_{1 \mathrm{x}}}{\phi_{\mathrm{p}} M_{\mathrm{ux}}}+0.85 \frac{M_{1 \mathrm{y}}}{\phi_{\mathrm{p}} M_{\mathrm{py}}} \leq 1
$$

when $\bar{\lambda}=\lambda_{\mathrm{y}} / \pi \sqrt{f_{\mathrm{y}} / E}<\bar{\lambda}_{p}$

$$
\begin{aligned}
& \varphi=1.0 \\
& \phi_{\mathrm{c}}=0.9 \\
& P \leq \phi_{\mathrm{c}} P_{\mathrm{u}}=\phi_{\mathrm{c}} \varphi \mathrm{A} f_{\mathrm{yk}}
\end{aligned}
$$

when $\bar{\lambda}_{p}<\bar{\lambda} \leq \dot{\lambda}_{\mathrm{e}}$

$$
\begin{aligned}
& \varphi=1-0.5\left(\dot{\lambda}_{-} \dot{\lambda}_{p}\right) /\left(\dot{\lambda}_{\mathrm{e}}-\dot{\lambda}_{p}\right) \\
& \phi_{\mathrm{c}}=0.9-0.05\left(\dot{\lambda}_{-}-\dot{\lambda}_{p}\right) /\left(\dot{\lambda}_{\mathrm{e}}-\dot{\lambda}_{p}\right) \\
& P \leq \phi_{\mathrm{c}} P_{\mathrm{uy}}=\phi_{\mathrm{c}} \varphi \mathrm{A} f_{\mathrm{yk}}
\end{aligned}
$$

when $\bar{\lambda}>\bar{\lambda}_{\mathrm{e}}$

$$
\begin{aligned}
& \phi_{\mathrm{c}}=0.85 \\
& P \leq \phi_{\mathrm{c}} P_{\mathrm{u}}=\phi_{\mathrm{c}} P_{E} / 1.2
\end{aligned}
$$

where

$$
P_{E}=f_{\mathrm{y}} / \overline{\lambda^{2}} \mathrm{~A}
$$

,that is $\varphi=1 /\left(1.2 \overline{\lambda^{2}}\right) ; M_{\mathrm{ux}}$ or $M_{\mathrm{uy}}=W f_{\mathrm{y}} ; M_{a x}$ or $M_{a x}=M * \frac{\beta}{1-\mathrm{P} / \mathrm{P}_{\mathrm{E}}} ; \bar{\lambda}_{p}=0.6-0.3 \frac{M_{2}}{M_{1}} ; \dot{\lambda}_{e}=$ $\sqrt{f_{\mathrm{y}} /\left(f_{\mathrm{y}}-\sigma_{\mathrm{cr}}\right)} ; \phi_{\mathrm{p}}$ and $\phi_{\mathrm{c}}=$ resistance factor $\sigma_{c r}=0.4 f_{\mathrm{y}} ; \dot{\lambda}=$ relative slenderness ratio; $P=$ ultimate load; $\varphi=$ stability factor; $\mathrm{A}=$ cross-sectional area; $W=$ section modulus; $f_{y}=$ yield stress; $\beta=$

\begin{tabular}{|c|c|c|c|c|c|c|c|c|c|c|c|}
\hline \multirow{2}{*}{$\begin{array}{l}\text { Type of } \\
\text { loading }\end{array}$} & \multirow{2}{*}{ Method } & \multicolumn{10}{|c|}{ Slenderness ratio } \\
\hline & & 10 & 20 & 30 & 40 & 50 & 60 & 70 & 80 & 90 & 100 \\
\hline \multirow{3}{*}{$\begin{array}{c}\text { Axial } \\
\text { load } \\
{[\mathrm{kN}]}\end{array}$} & Simulation & 3499 & 3378 & 3255 & 3105 & 2905 & 2688 & 2425 & 2145 & 1878 & 1631 \\
\hline & $\begin{array}{l}\text { Simulation with } \\
\text { imperfection }\end{array}$ & 3462 & 3316 & 3163 & 2982 & 2749 & 2515 & 2249 & 1982 & 1733 & 1510 \\
\hline & Chinese code & 3059 & 2977 & 2868 & 2724 & 2533 & 2291 & 2011 & 1731 & 1481 & 1271 \\
\hline
\end{tabular}
equivalent moment factor; $M_{1}$ and $M_{2}=$ end moment.

\section{Comparison of theoretical calculation and simulation}

Simulation and theoretical calculation results are listed in table 3. Ultimate load is shown in Fig. 5. It suggested that simulation results with imperfection was slightly larger than calculation results. Calculation results by the code were slightly different. That was reason that the residual stress was not considered in simulation However, the results calculated by Chinese code were slightly larger than others when the slenderness ratio was in the range 40 to 70 . The curve calculated by code was similar with simulation.

Table 3 Ultimate load of different method 


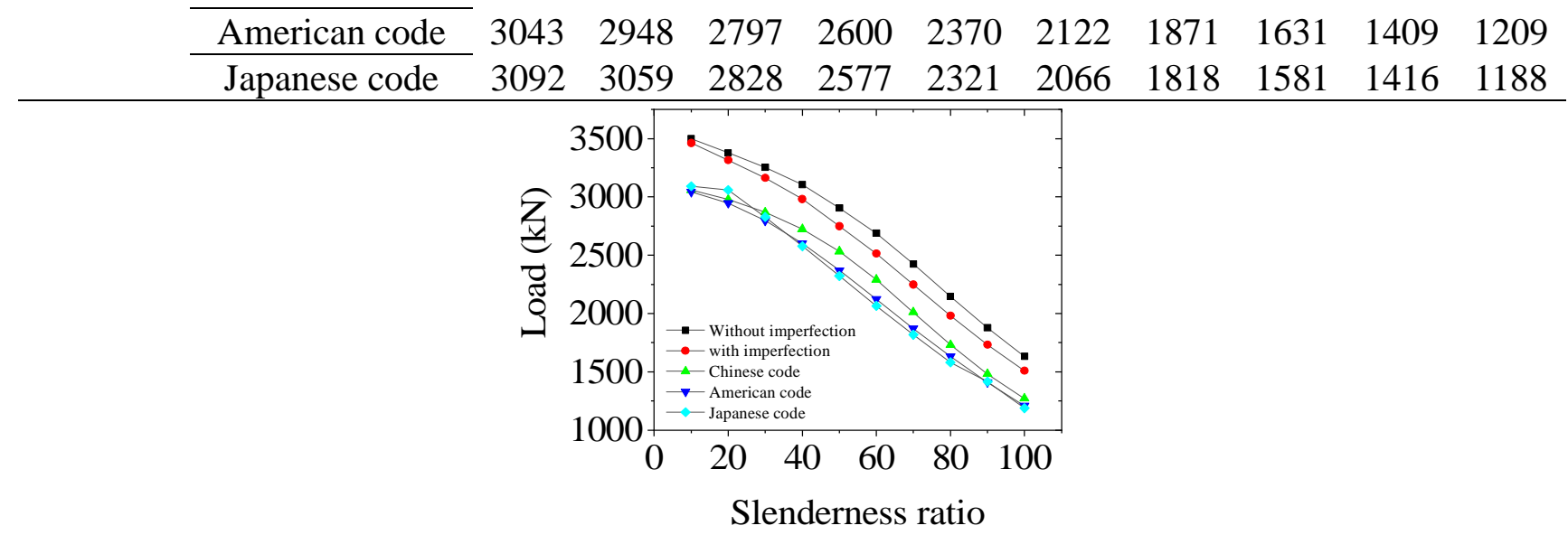

Fig. 5 Ultimate load of different methods

\section{Conclusions}

(1) The curve calculated by code is similar with simulation.

(2) Results calculated by different codes is similar.

(3) Ultimate load reduces as the slenderness ratio increases.

(4) First, the value of critical slenderness ratio is 50, which reflects the transition of ductility and instability.

(5) Simulation with imperfection is in good agreement with results calculated by codes. It indicates that it is feasible to apply initial imperfections in the form of equivalent eccentricity.

\section{Acknowledgements}

This work was supported by the Science Fund for Creative Research Groups of the National Natural Science Foundation of China (No. 51408378) and the Creative Research Groups of the Hebei Province Natural Science Foundation of China (No. E2015403018).

\section{References}

[1] ANSI/AISC 360-10. Specification for Structural Steel Buildings, Chicago: American Institute of Steel Construction, 2005.

[2] AIJ2010. Design standard steel structure, Tokyo: Architectural Institute of Japan, 2010.

[3] J. Chen, Stability of steel structures theory and design, Beijing: Science Press, 2014.

[4] GB50010-2010. Code for design of steel structures, Beijing: China Architecture \& Building Press, 2010.

[5] G.W. Li and Li, Y.Q, Overall stability behavior of axially compressed cold-formed thick-walled steel tubes, Thin-Walled Structures, 125(2018): 234-244.

[6] H.M. Pan, Y.L. Guo, and S. Liang, A stability analysis of major diameter thin-walled tube beam-columns, China Civil Engineering Journal, 40(2007): 11-17.

[7] L.Y. Yang, Z.L. Li, and L. Wei, et all, An investigation of high strength steel tubes' ultimate load capacity under axial compression, J. Xi' an Univ. of Arch. \& Tech (Natural Science Edition) 42(2010): 201-204.

[8] J.B. Yang, Research on determining slenderness ratio of members of super high voltage transmission steel tubular towers, Engineering Journal of Wuhan University, 42(2009): 245-248. 